\title{
¿Qué puede enseñarle la epidemiología de las enfermedades infecciosas a la epidemiología de las enfermedades crónicas?
}

\author{
What does the epidemiology of infectious diseases \\ have to teach the epidemiology \\ of chronic diseases?
}

El estudio de las enfermedades infecciosas ha sido históricamente una de las características patognomónicas de la epidemiología. Muchos de los ejemplos que se utilizan para ilustrar conceptos epidemiológicos en la docencia parten de casos de enfermedades infecciosas. El inglés John Snow, a menudo considerado uno de los pioneros del método epidemiológico, se dedicó a investigar las causas del cólera en Londres en el siglo XIX. El húngaro Ignaz Semmelweis intuyó los agentes infecciosos como causa fundamental de la fiebre puerperal. El francés Louis Pasteur identificó las bacterias causantes de diversas enfermedades y produjo las primeras vacunas. El alemán Heinrich Hermann Robert Koch aisló los gérmenes causantes del carbunco (Bacillus anthracis), la tuberculosis (Mycobacterium tuberculosis) y el cólera (Vibrio cholerae) y desarrolló los postulados que hoy se conocen por su nombre y se usan para determinar si un germen es o no causal.

En nuestra época, los casos más conocidos de avances epidemiológicos se refieren a enfermedades infecciosas: la identificación del virus del sida y los factores de riesgo asociados; el control de las epidemias recientes de SRAG (el síndrome respiratorio agudo grave) o de gripe e, incluso, la identificación reciente de un hongo como causa de los casos de meningitis asociados a inyecciones intratecales de corticoides en EE.UU. El nombre mismo de la disciplina hace referencia a "epidemias" y en su acepción original se refería al estudio de las enfermedades infecciosas (parece que el término "epidemiología" se usó por primera vez en documentos españoles del siglo XV). Incluso hoy, las enfermedades crónicas como el cáncer o las enfermedades cardiovasculares, que en casi todos los países superan ya a las enfermedades infecciosas como causas de morbilidad y mortalidad a nivel poblacional, se definen en contraposición directa a las enfermedades infecciosas como "enfermedades no transmisibles". El público general tiende a identificar a la epidemiología casi exclusivamente con el estudio de las grandes epidemias de enfermedades infecciosas.

Este vínculo de la epidemiología con las enfermedades infecciosas ha tenido un impacto profundo en sus conceptos y sus métodos. La teoría de los gérmenes, que al desplazar a la teoría miasmática instaló la búsqueda de algún organismo microbiano como causa de cada proceso patológico, ha influido decisivamente en la concepción de causa en epidemiología y ha enfatizado la noción de causa necesaria y suficiente (la presencia del germen) que caracterizó al pensamiento causal clásico. Esta concepción de causa se trasladó en cierta medida a la conceptualización de los factores de riesgo a nivel individual (los comportamientos individuales, por ejemplo) como causas necesarias y suficientes de las enfermedades crónicas, sobre todo en el caso paradigmático de la enfermedad cardiovascular. De 
hecho, el objetivo último de muchos diseños y análisis epidemiológicos actuales -aislar el posible efecto causal de un factor determinado- tiene paralelismos con la idea de aislar el germen causal de una enfermedad infecciosa. En ese sentido, si bien los orígenes de la epidemiología en las enfermedades infecciosas han fomentado una búsqueda de especificidad causal que ha sido útil para la salud pública en general, también han fomentado un reduccionismo que ha Ilevado a limitar la capacidad explicativa de la epidemiología no solo para otros trastornos de la salud sino incluso para muchas enfermedades infecciosas.

En muchos casos, el estudio epidemiológico de las enfermedades infecciosas ha enfatizado la identificación del germen causal como causa única, necesaria y suficiente, pero también es verdad que la epidemiología de las enfermedades infecciosas ha reconocido con creces la insuficiencia de esas explicaciones reduccionistas. Una primera manera de superar el reduccionismo unicausal es reconocer la importancia de las características del huésped como modificadoras del efecto de la presencia del germen. En El espejismo de la salud, René Dubos discutió en detalle cómo incluso en la mayoría de las enfermedades la presencia del germen no es condición suficiente para causar enfermedad. Debe combinarse con características del huésped que a menudo se ven fuertemente influidas por el ambiente en el que este se encuentra. De hecho, hay muchos casos de gérmenes que habitan en el huésped sin causar patología (Mycobacterium tuberculosis es un ejemplo clásico). Solo se manifiestan como enfermedad en el caso de alteraciones inmunitarias asociadas por ejemplo a deficiencias nutricionales o a exposiciones a situaciones estresantes para el organismo. Una segunda manera en que la epidemiología de las enfermedades infecciosas ha superado el reduccionismo unicausal es reconocer la importancia del ambiente en la reproducción y en la trasmisión del germen. Esto indica que la probabilidad de adquirir el germen y la enfermedad se encuentra fuertemente influenciada por el ambiente social y físico en el que se encuentra el individuo. Ambos procesos, la influencia de las características del huésped en la respuesta del organismo a la presencia del germen y la influencia del ambiente en la probabilidad de que el huésped adquiera el germen, implican un modelo multicausal con varios niveles de influencia. Los artículos recopilados en este número monográfico de Salud Colectiva sobre enfermedades infecciosas ilustran con claridad esta necesidad de considerar múltiples niveles de influencia y contextualizar el estudio epidemiológico de las enfermedades infecciosas.

Pero hay una tercera manera de ir más allá del reduccionismo unicausal que ha cobrado vigencia creciente en los últimos años, no solo en la epidemiología de las enfermedades infecciosas sino en otros campos de la epidemiología. Por definición, la naturaleza transmisible de las enfermedades infecciosas implica que la condición de un individuo influye en la salud de los que lo rodean. En otras palabras, hay múltiples patrones de dependencia entre los individuos, y el estado de salud o enfermedad de un individuo no es independiente del estado de los individuos que viven en su mismo ambiente o que pertenecen a sus redes sociales. Esto implica la presencia de influencia mutua, patrones de retroalimentación y relaciones no lineales que caracterizan a los sistemas dinámicos. A menudo, comprender el efecto de un factor en particular requiere comprender las reglas básicas que caracterizan el funcionamiento del sistema en su totalidad. Es por eso que la epidemiología de las enfermedades infecciosas ha estado a la vanguardia de la utilización de técnicas de modelado de sistemas complejos en la epidemiología y en la salud pública en general.

Es interesante observar que la necesidad de concebir la salud poblacional y los fenómenos epidemiológicos en general como el resultado del funcionamiento de un sistema ha cobrado vigencia creciente en otras áreas de la epidemiología. Por ejemplo, estudios recientes han sugerido la posibilidad de que los comportamientos asociados a enfermedades crónicas sean también "transmisibles" a través de redes sociales, de manera análoga a la transmisión de un germen. También se ha hablado a menudo de la necesidad de utilizar los conceptos y las herramientas derivadas del estudio de los sistemas complejos en la práctica de la epidemiología y de la salud pública en general. Por supuesto que la utilización de estos conceptos y herramientas también puede plantear problemas ulteriores, sobre todo cuando se intenta aplicarlos para comprender fenómenos mucho más complejos que la transmisión de un germen a través de redes sociales. 
Es importante destacar que, a lo largo del tiempo, la distinción entre enfermedades transmisibles y enfermedades crónicas se ha vuelto cada vez más tenue y artificial. Por ejemplo, se sabe que muchas enfermedades consideradas como enfermedades crónicas por excelencia, como la arteriosclerosis o las enfermedades cardiovasculares en general, pueden tener orígenes infecciosos. Al mismo tiempo hay enfermedades infecciosas como el sida que, con el tiempo y el avance de los tratamientos, se han convertido de hecho en enfermedades crónicas. En resumen, tanto las enfermedades crónicas como las enfermedades infecciosas tienen determinantes a múltiples niveles y, en última instancia, son la manifestación del funcionamiento de sistemas complejos en los que los individuos interactúan entre sí y con su ambiente a lo largo del tiempo. Los artículos de este número monográfico nos invitan a reflexionar sobre cómo influyen en los patrones epidemiológicos los diversos factores que se extienden desde la organización social y económica de una sociedad hasta las características biológicas de un germen. La integración de esos factores, de manera que permita sintetizar las relaciones más importantes e identificar las acciones más útiles para mejorar la salud, sigue siendo la tarea más importante de la epidemiología.

Diez Roux, Ana V.

Doctora en Epidemiología. Profesora y Directora del Departamento de Epidemiología, Directora, Center for Social Epidemiology and Population Health; School of Public Health; University of Michigan, EE.UU.

\section{FORMA DE CITAR}

Diez Roux AV. ¿Qué puede enseñarle la epidemiología de las enfermedades infecciosas a la epidemiología de las enfermedades crónicas? [Editorial]. Salud Colectiva. 2012;8(Supl 1):S5-S7. 